\title{
Characterization of volatile and odor-active compounds of the essential oil from Bidens graveolens Mart. (Asteraceae)*
}

\author{
Ana C. R. Silva ${ }^{1}$ (D) | Humberto R. Bizzo ${ }^{2}$ | Roberto F. Vieira ${ }^{3}$ | João B. A. Bringel Jr $^{3}$ | \\ Débora A. Azevedo $^{4}$ | Thais M. Uekane ${ }^{5}$ | Claudia M. Rezende ${ }^{1}$
}

\author{
${ }^{1}$ Laboratory of Aroma Analysis, Federal \\ University of Rio de Janeiro, Rio de Janeiro, \\ RJ, Brazil \\ ${ }^{2}$ Embrapa Agroindústria de Alimentos, Rio \\ de Janeiro, RJ, Brazil \\ ${ }^{3}$ Embrapa Recursos Genéticos e \\ Biotecnologia, Brasilia, DF, Brazil \\ ${ }^{4}$ Laboratory of Molecular and Environmental \\ Geochemistry, Federal University of Rio de \\ Janeiro, Rio de Janeiro, RJ, Brazil \\ ${ }^{5}$ Fluminense Federal University, Santa Rosa, \\ Niterói, RJ, Brazil

\section{Correspondence} \\ Ana C. R. Silva and Claudia M. Rezende, \\ Laboratory of Aroma Analysis, Federal \\ University of Rio de Janeiro - Avenida Athos \\ da Silveira Ramos, 149, Cidade Universitária, \\ Rio de Janeiro, RJ, Brazil. \\ Emails: acarolinarosa.16@gmail.com (A. C. \\ R. S.) and claudia.rezendeufrj@gmail.com \\ (C. M. R.)

\section{Funding information} \\ Empresa Brasileira de Pesquisa \\ Agropecuária; Coordenação de \\ Aperfeiçoamento de Pessoal de Nível \\ Superior, Grant/Award Number: Finance \\ code 001; Fundação de Amparo a Pesquisa \\ do Rio de Janeiro (FAPERJ); Conselho \\ Nacional de Desenvolvimento Científico e \\ Tecnológico
}

\begin{abstract}
During a bioprospection study in the Brazilian Cerrado, samples of Bidens graveolens Mart., an endemic species, were investigated. Chemical and olfactive analyses were performed on the essential oil obtained from fresh leaves of $B$. graveolens collected in November 2013 (BG1) and May 2014 (BG2). A total of 60 compounds were identified in the essential oil extracted from fresh leaves, by hydrodistillation. The main constituents were identified as monoterpene hydrocarbons, ranging from $86.5 \%$ to $89.6 \%$. Limonene was the major compound, accounting for $22.8 \%$ in BG1 and $47.7 \%$ in BG2. Thirty-three-oxygenated monoterpenes were identified, comprising about $9 \%$ in both essential oils (EO). The attributes described by the panelists are in accordance to the sensorial profile. Myrcene, limonene, epoxy-myrcene, and limonene dioxide were rated by all panelists. Present at a frequency of $83.3 \%, \alpha$-pinene, $\beta$-pinene, $\alpha$-pinene oxide, and carvone were picked out by five panelists. It is noteworthy that most compounds rated with the highest intensity score belonged to the oxygenated monoterpene class, considered the most expressive terpene class used in perfumery. In general, these compounds were described as presenting green, herb, spicy, fresh, and camphoraceus odors.
\end{abstract}

\section{KEYWORDS}

B graveolens, chemical composition, essential oil, GC-O, odor-active compounds

\section{1 | INTRODUCTION}

The Cerrado is the second major Brazilian biome, covering near $25 \%$ of the country's national territory. It is considered a biodiversity hotspot, that is, presenting high concentrations of endemic species under strong anthropic pressure. ${ }^{1,2}$ Although over 12000 plant species have been cataloged in this biome, studies regarding the identification of their volatile chemical compounds are still lacking. ${ }^{3}$ To the best of our knowledge, except for Eremanthus erythropappus DC.

*Part 9 in the series: Scents from the Brazilian Cerrado.
MacLeish (syn Vanillosmopsis erythropappa, Asteraceae), no other native Cerrado species are currently used for essential oil production on an industrial scale.

The Bidens genus belongs to the Asteraceae family and comprises approximately 240 species distributed throughout the Americas, Africa, Europe, and Asia. ${ }^{4-6}$ Nineteen Bidens species are estimated to exist in Brazil, and at least six are endemic to the Cerrado biome. ${ }^{6,7}$ The biological properties of essential oils from some Bidens have been investigated, including antimicrobial, antioxidant, antifungal, and cytotoxic activities. ${ }^{4,5,8-13}$ The essential oils from $B$ pilosa, $B$ frondosa, and $B$ tripartite have been tested as 
natural preservatives, intended to extend the shelf life of certain food products. ${ }^{4,5,8,13}$

A large bioprospection project concerning aromatic Cerrado species was conducted by Embrapa from 2012 to 2018. Over 300 samples from 134 different plant species were collected, and their essential oils were distilled and chemically and sensorially analyzed. The sensorial analyses were performed by a senior perfumist from Givaudan, an Embrapa partner in this enterprise, and some of the results have been published. ${ }^{3,14,15}$ One of the assessed species in the project was Bidens graveolens. The first report concerning this plant appeared in 1983, in which a petroleum ether extract was investigated and sesquiterpenoids, including germacrene D and spathulenol, were the major detected compounds. ${ }^{16}$ Regarding essential oils, a preliminary report was presented in a conference abstract by our research group regarding a sample collected in April 2012, in which $\alpha$-pinene and limonene were the major compounds identified. ${ }^{17}$ To the best of our knowledge, no other reports on the chemical composition or odor characteristics of $B$ graveolens have been published. In this context, the aim of this study was to identify and quantify volatile compounds present in the essential oil (EO) obtained from $B$ graveolens leaves as well as carry out an odor analysis by olfactometry (GC-O).

\section{2 | EXPERIMENTAL}

\section{1 | Standards}

A mix of hydrocarbons ranging from $n-C_{8}-C_{28}$, obtained from Sigma-Aldrich (USA), was used to calculate the retention indices. The following compounds were used to measure the response factors: $\alpha$-pinene, $\gamma$-terpinene, $p$-cymene for monoterpene hydrocarbons; linalool, menthol, nerol, carvone, linalool oxide for oxygenated monoterpenes; benzyl alcohol for aromatic alcohols; geranyl acetate, menthyl acetate, for esters; $(E)$ - $\beta$-caryophyllene for sesquiterpene hydrocarbons and $\alpha$-bisabolol for oxygenated sesquiterpenes. All were purchased from Sigma-Aldrich and Fluka, at a purity degree of at least $95 \%$. Analytical-grade hexane and dichloromethane were purchased from Tedia (Brazil) and Vetec Quimica Fina (Brazil).

\section{2 | Plant material}

B graveolens Mart. leaves were collected from two populations ( $\mathrm{n}>5$ for each population) at Chapada dos Veadeiros, Goiás, Brazil,

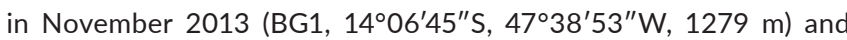

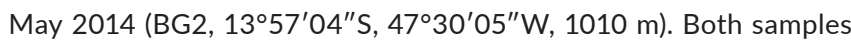
were collected during the flowering phase. Botanical identifications were performed by Dr. João Bernardo Bringel Junior, and voucher specimens were deposited at the Embrapa Genetic Resources and Biotechnology herbarium (CEN 88280 for BG1, and 88409 for BG2) in Brasilia, DF, Brazil. All collection and analyses were authorized by the Brazilian Ministry of Environment (IBAMA process 02001.003166/2013-26).

\section{3 | Hydrodistillation}

Fresh BG1 and BG2 leaves (208.0 and 200.0 g, respectively) were subjected to hydrodistillation in the same day of the collection, using $a$ in a modified Clevenger-type apparatus for 2 hours. After distillation, the EOs were collected, dried with anhydrous sodium sulfate $\left(\mathrm{Na}_{2} \mathrm{SO}_{4}\right)$, and maintained at $8-10^{\circ} \mathrm{C}$ until analyses.

\section{4 | Sensory analyses}

The essential oil BG2 ( $2 \%$ in ethanol) was randomly evaluated on smelling paper strips by ten trained panelists (three men and seven women) during three consecutive days. The panelists were trained during 3 days to evaluate extracts and pure compounds, providing relevant vocabulary and correct olfactive families, defined internally. Panelists were asked to give an intensity score from 0 (no odor) to 4 (maximum intensity) for ten olfactive descriptors previously defined with the aid of perfumists: camphor, green, fruity, fresh, floral, citric, spicy, amber, and musk. These panelists also participated in the GC-O session. ${ }^{18,19}$

\section{5 | Gas chromatography}

\subsection{1 | Gas Chromatography GC(FID)}

Analyses were performed using a GC(FID) 6890 (Agilent Technologies, Wilmington, NC, USA), with a double injection port, equipped with a DB-5 nonpolar column (30 m $\times 0.25 \mathrm{~mm}$ internal diameter, $0.25 \mu \mathrm{m}$ film thickness; Agilent). Next, $1.0 \mu \mathrm{L}$ of the diluted essential oils was injected in split mode (1:20), with the injector temperature maintained at $220^{\circ} \mathrm{C}$. The oven temperature was programmed from 38 (3 min) to $180^{\circ} \mathrm{C}$ at $3^{\circ} \mathrm{C} / \mathrm{min}$ and from 180 to $240^{\circ} \mathrm{C}$ at $20^{\circ} \mathrm{C} / \mathrm{min}$. Hydrogen was used as the carrier gas at a flow rate of $1.0 \mathrm{~mL} / \mathrm{min}$. The detector temperature was maintained at $280^{\circ} \mathrm{C}$. The $\mathrm{H}_{2}$ /air ratio was of $10 \%$, and the airflow rate was of $400 \mathrm{~mL} / \mathrm{min}$.

Quantification was performed by internal standardization with the use of experimental relative response factors (RRF) and $n$-octadecane as an internal standard. Authentic standards, each representing a chemical class to be determined, were selected among those available at the laboratory. Three replicates of mixtures containing equal amounts of the internal standard ( $n$-octadecane, $0.1 \mathrm{mg} / \mathrm{mL}$ ) and the representative compounds diluted in dichloromethane were analyzed, at five concentrations. For each representative compound within a chemical class, a calibration curve, based on the internal standard (IS) to the reference analyte (C) peak area ratio vs. the internal standard (IS) to the reference analyte $(C)$ concentration ratio was plotted. Whenever possible, more than one standard per class was used, and the RRF was calculated by the means of the slopes of all representative compounds. ${ }^{20-22}$

\subsection{2 | Gas Chromatography-Mass Spectrometry (GC-qMS)}

Analyses were performed using a GC 6890 hyphenated to a MSD $5073 \mathrm{~N}$ (Agilent Technologies) using the same column described in 
the GC-FID section. Next, 1.0 $\mu \mathrm{L}$ of the diluted EO was injected in split mode (1:20) and the injector temperature was maintained at $220^{\circ} \mathrm{C}$. Oven temperature program varied from 60 to $180^{\circ} \mathrm{C}$ at $3^{\circ} \mathrm{C} /$ min and 180 to $240^{\circ} \mathrm{C}$ at $20^{\circ} \mathrm{C} / \mathrm{min}$. The MS detection was performed in scan mode in the 40-450 Da range with temperatures set at $150^{\circ} \mathrm{C}$ and $230^{\circ} \mathrm{C}$ for the quadrupole and the El source, respectively, with an electron multiplier voltage of $1145 \mathrm{~V}$.

The analytes were identified by comparing of their mass spectra and retention indices ( \pm 10 units) to the Wiley Registry of Mass Spectral Data ${ }^{\circledR}(1994)$ or the NIST $^{\circledR}$ database (2013), as well as literature data. ${ }^{23}$

\subsection{3 | Gas Chromatography-Olfactometry (GC-O)}

The EO BG2 was diluted to $10 \%(\mathrm{v} / \mathrm{v})$ in hexane and injected into an Agilent 6890-5973N GC-MS system, fitted with a Gerstel ODP 2 olfactometric port. The analytical column and chromatographic conditions were the same as stated above. For the GC-O analysis, a Deans Switch (DS) G2855A(Agilent Technologies) was used to direct the flow to both the olfactometric port and the mass detector, using capillary columns without a stationary phase $(0.90 \mathrm{~m} \times 0.2 \mathrm{~mm}$ internal diameter and $1.16 \mathrm{~m} \times 0.15 \mathrm{~mm}$ internal diameter, Agilent). The detection frequency method was employed and six trained panelists (three women and three men) participated in the olfactometry experiments. These panelists were familiar with sensorial analysis techniques and were previously trained using reference aromatic compounds. The EOs were randomly evaluated three times to ensure intermediate precision of the panel. The evaluation consisted of the detection of odor-active compounds by the assessors, accompanied by qualitative descriptions. The answers were only considered when given by the same panelist twice out of the three runs. Substances with over $50 \%$ of detection (more than three perceptions) were considered odorant compounds for the EO. ${ }^{18,19}$ The sniffing procedure was divided into 12 min sessions with 10 min intervals, in order to avoid lassitude.

\section{3 | RESULTS AND DISCUSSION}

\section{1 | Volatile composition}

The essential oil yields, calculated on a dry basis, were $0.25 \%$ for both BG1 and BG2, similar to those reported in studies carried out with other plants of this genus. ${ }^{4,5,24,25}$

The EOs were analyzed by GC-MS and quantified by GC-FID using internal standards and RFFs. The RFFs values are presented in Table 1, while the volatile constituents identified and quantified in fresh leaf BG1 and BG2 EOs are displayed in Table 2, alongside the components listed according to their order of elution on a DB-5 column. The chromatogram profiles of the two EO are presented in Figure 1.

Sixty components were identified, representing $99.7 \%$ of the EO compositions, which were richer in monoterpene hydrocarbons, especially BG2, representing almost $90 \%$, and limonene, which appeared as the major compound (47.7\%). Other major compounds were identified as $\alpha$-pinene (21.0 and 18.3\% in BG2 and BG1, respectively), $\beta$-pinene (14.2 and $14.9 \%$, respectively) and (Z)- $\beta$-ocimene (13.2\%, only in BG1).

The main compounds detected in an EO from dried $B$ graveolens leaves assessed by Silva et al (2012) were $\alpha$-pinene (16.6\%), sabinene/ $\beta$-pinene (11.1\%), $\alpha$-phellandrene (5.9\%), and limonene (25.0\%). ${ }^{17}$ The volatile composition of an EO is determined by the genetics of each plant, and is specific to each organ and plant development stage. In addition, environmental conditions may also significantly alter EO composition. ${ }^{26}$ Therefore, the major cause for the difference in the $B$ graveolens EO composition assessed by Silva et al and the EOs of the present study may be due to differences in the plant sampling dates. In the present study, leaves were collected in May 2014 (BG2) and November 2013 (BG1), while Silva et al samples the assessed plant in April 2012. In other studies carried out with Bidens plants, monoterpene hydrocarbons accounted for less than $20 \%$ of the total leaf EO composition., ${ }^{4,5}$
TABLE 1 Experimental relative response factors (RFFs), expressed as the slope of the regression line, for different volatile classes in B graveolens leaf EOs

\begin{tabular}{|llll}
\hline Compound Class & Compounds & RFF & Mean RF \pm STD \\
\hline Hydrocarbon monoterpenes & $\gamma$-terpinene & 1.06 & \\
& $\alpha$-pinene & 1.07 & $1.05 \pm 0.03$ \\
& $p$-cymene & 1.02 & \\
\hline Oygenated monoterpenes & linalool & 1.48 & \\
& menthol & 1.28 & \\
& nerol & 1.44 & $1.48 \pm 0.13$ \\
& carvone & 1.64 & \\
\hline Aromatic alcohols & linalool oxide & 1.54 & \\
\hline Monoterpene esters & benzyl alcohol & 1.76 & 1.76 \\
\hline Sesquiterpene Hydrocarbon & menthyl acetate & 1.10 & $1.24 \pm 0.21$ \\
\hline Oxygenated sesquiterpene & geranyl acetate & 1.39 & \\
\hline
\end{tabular}


TAB LE 2 Chemical composition of B graveolens leaf essential oils

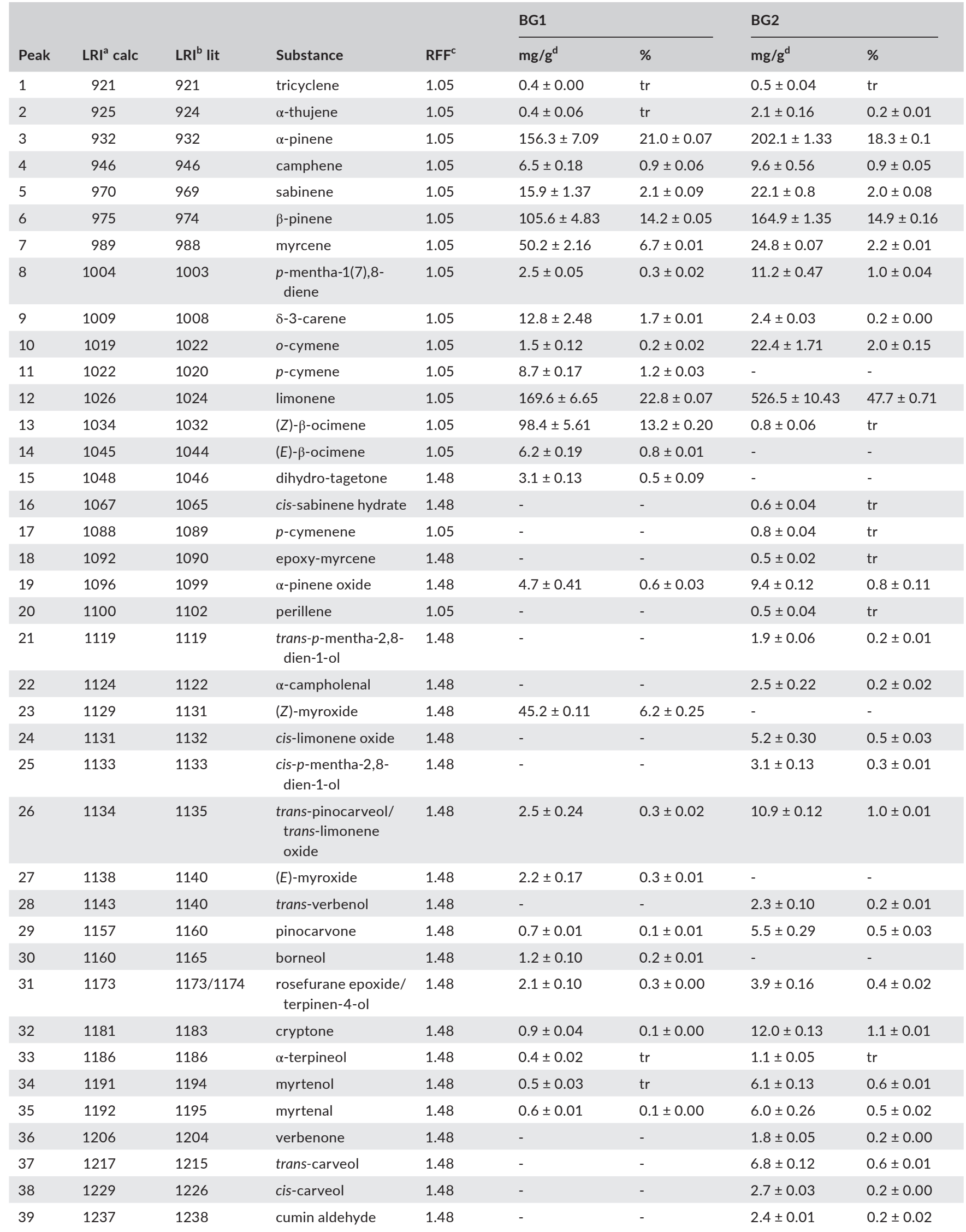


TABLE 2 (Continued)

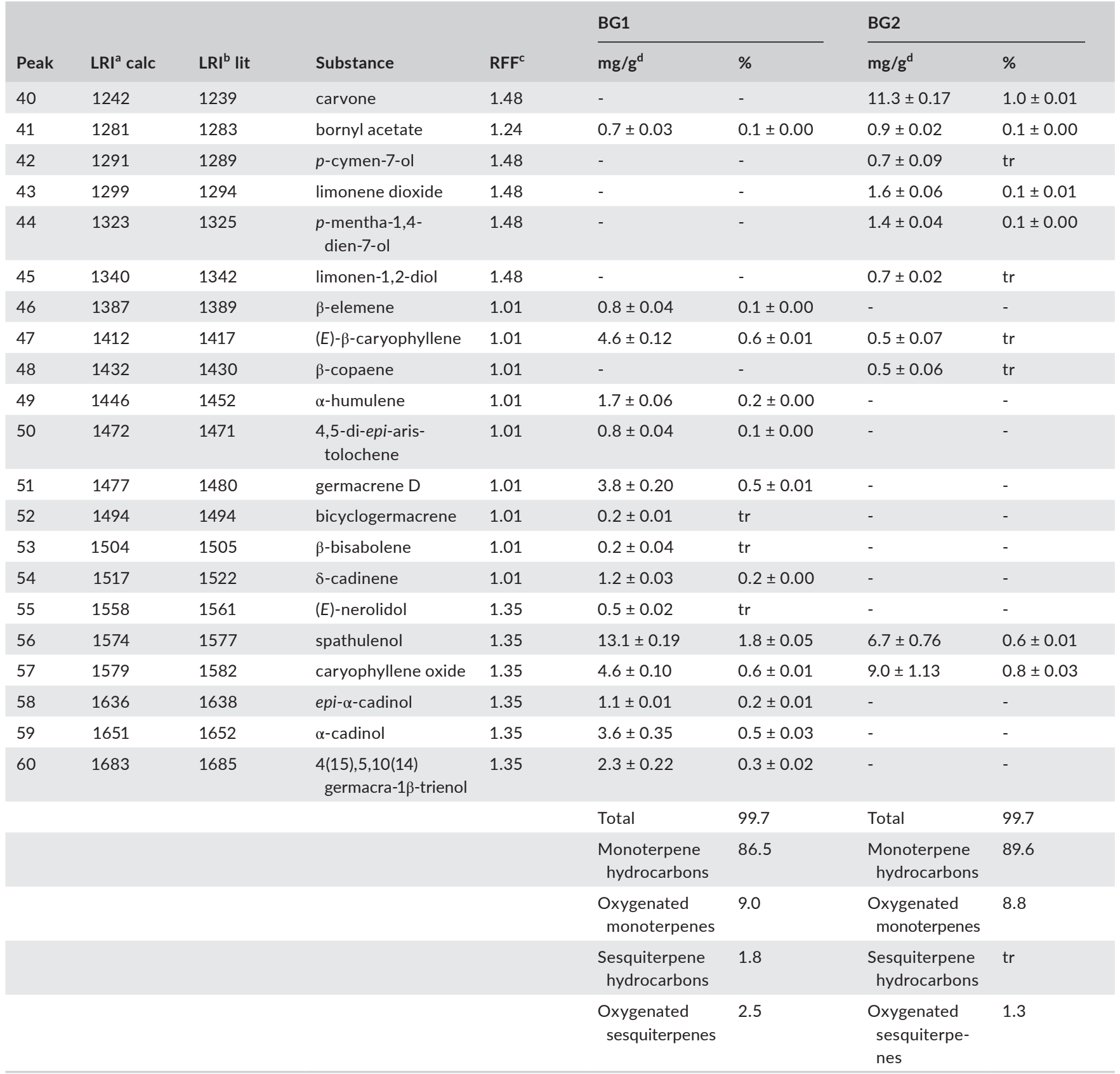

${ }^{\mathrm{a}} \mathrm{LRI}_{\text {calc }}=$ On DB-5 column .

${ }^{\mathrm{b}} \mathrm{LRI}_{\text {lit }}=$ from reference 18 .

crelative response factor from 1 .

${ }^{d} \mathrm{mg}$ of the compound per gram of essential oil; $\mathrm{tr}=$ trace $(<0.1 \%)$.

A total of 25 oxygenated monoterpenes were identified in BG2 and 12 in BG1, representing about $9 \%$ of the relative EO area. $\alpha$ Pinene oxide, pinocarvone, trans-pinocarveol, trans-limonene oxide, rose furane epoxide, cryptone, myrtenol, and myrtenal were found in both EOs and described for the first time in an EO from this genus. Oxygenated monoterpenes such as epoxy-myrcene, $\alpha$-pinene oxide, trans-pinocarveol, trans-verbenol, cis and trans-carveol, carvone, and limonene dioxide were observed only in BG2. Since the oil was distilled in the same day of plant collection, kept in the dark under reduced temperature and analyzed no more than a week later, it does not seem feasible these epoxides were present due to aging of the essential oil after distillation.

Sesquiterpene hydrocarbons have been reported as the major compounds in other studies carried out with Bidens EOs, , ${ }^{4,5,27}$ In the present study, this class comprised about $2 \%$ of the chemical composition of the BG1 EO. In essential oils from fresh B sulfurea and B pilosa leaves, sesquiterpenes represent $95.8 \%$ and $35.9 \%$, respectively of total EO composition. ${ }^{4,25}$ 
The findings demonstrate differences between the chemical EO compositions, especially in the sesquiterpene group. Concerning plant collection dates, a distinct difference between climate and rainfall regime in the cultivation area is noted, and environmental factors have been reported as influencing the storage of volatile compounds in secretory plant structures. ${ }^{26,28}$

\subsection{Characterization of BG2 odor- active compounds}

The olfactive descriptors green, fresh, spicy, camphor, fruity, and floral were used by panelists to characterize the BG2 EO in the sensory analysis. This EO was considered by the perfumer as one of the more interesting samples, with its odor described as "...green and mustard leaves, coriander, and watery fruits." The attributes described by the panelists are in accordance to the sensorial profile observed in the perfumist evaluation. The herbal and spicy odors are related to the description of green notes that are associated to coriander, while camphoraceous refers to a camphor odor and fresh and fruity odors may refer to the fresh fruit odor.

Sensory analyses can indicate essential oil odor descriptions, but it is not possible to identify which volatile compounds are responsible for the described odor. To obtain this information, a more complex analysis is required, and one of the main techniques currently applied is GC-O.

The GC-O using detection frequency method allowed for the determination of odor-active compounds with minimum panelist time and training. ${ }^{29}$ Six panelists participated in the analysis and considered as main $B$ graveolens OE odor compounds those observed at $100 \%$ of frequency detection (FD, detected by all panelists). Substances presenting over 66\% FD, that is, detected by at least two panelists, were accepted as odoriferous compounds.

\section{(A)}

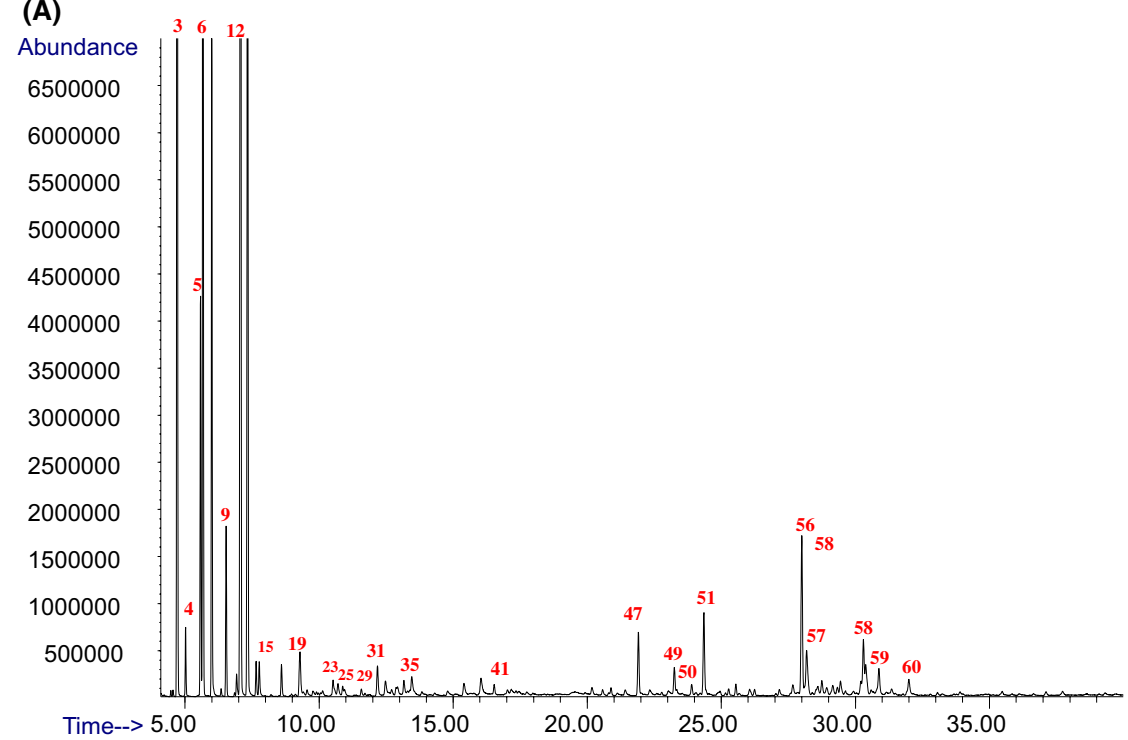

(B)

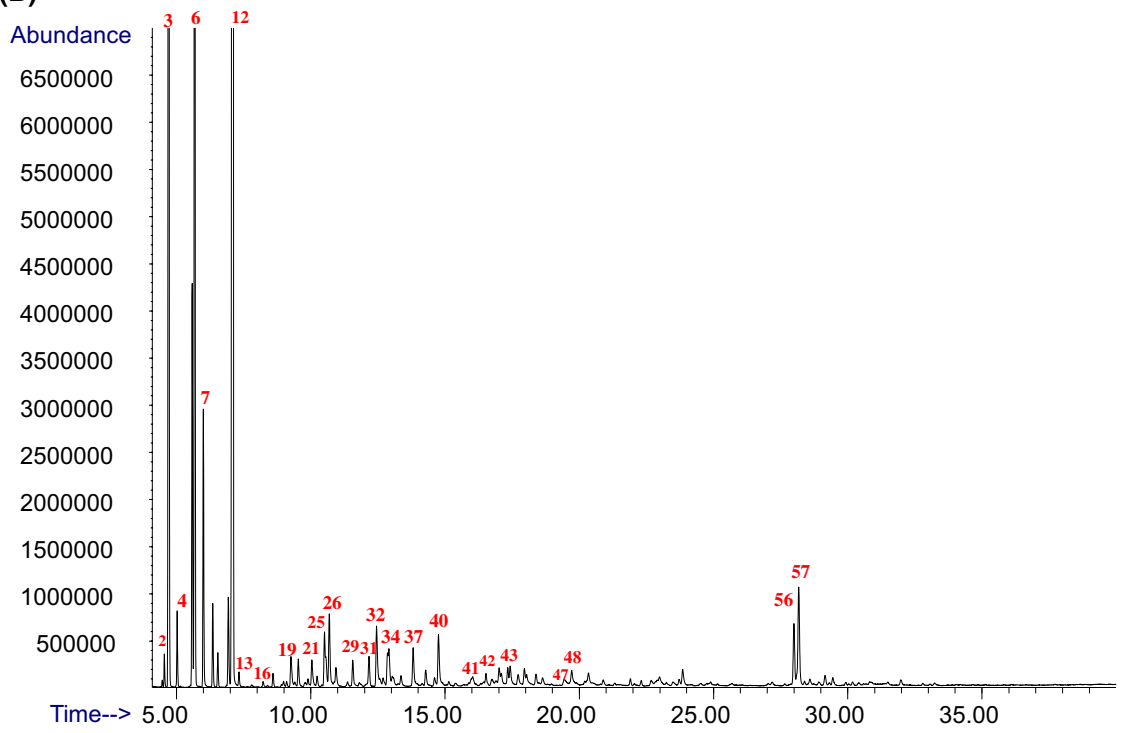

FIGURE 1 Representative total ion chromatograms of essential oils from B graveolens. (A) BG1; (B) BG2. peak numbers correspond to those listed in 2. [Colour figure can be viewed at wileyonlinelibrary.com] 
TAB LE 3 Odor-active compounds in essential oil BG2 according to the frequency detection method and odor descriptors indicated by the panelists

\begin{tabular}{|c|c|c|c|c|}
\hline Peak & Substance & $\Sigma \mathrm{Ni}$ & Descriptors & $\%$ FD \\
\hline 3 & $\alpha$-pinene & 5 & Grass, floral, and citrus & 83.33 \\
\hline 6 & $\beta$-pinene & 5 & Spicy, fresh, grass, and green & 83.33 \\
\hline 7 & myrcene & 6 & Green, and camphor & 100.00 \\
\hline \multirow[t]{3}{*}{12} & Limonene & 6 & Floral, fruity, fresh, and green & 100.00 \\
\hline & $<L D$ & 3 & - & 50.00 \\
\hline & N.I. & 3 & Herb, green, camphor, and fresh & 50.00 \\
\hline 18 & epoxy-myrcene & 6 & Green, mint, and spicy & 100.00 \\
\hline \multirow[t]{2}{*}{19} & $\alpha$-pinene oxide & 5 & Fruity and citrus & 83.33 \\
\hline & N.I. $M M=154$ & 6 & Spicy and green & 100.00 \\
\hline 26 & trans-pinocarveol/trans-limonene oxide & 2 & Citrus and floral & 33.33 \\
\hline \multirow[t]{2}{*}{28} & trans-verbenol & 2 & Herb & 33.33 \\
\hline & $<L D$ & 3 & - & 50.00 \\
\hline 37 & trans-carveol & 5 & - & 83.33 \\
\hline \multirow[t]{2}{*}{40} & carvone & 3 & Spicy, fresh, and citrus & 50.00 \\
\hline & N.I. & 6 & - & 100.00 \\
\hline \multirow[t]{2}{*}{43} & Limonene dioxide & 3 & Spicy, fresh, and citrus & 50.00 \\
\hline & N.I. & 3 & Fresh & 50.00 \\
\hline 59 & caryophyllene oxide & 2 & - & 33.33 \\
\hline
\end{tabular}

Abbreviations: FD, frequency detection; <LD, below the limit of detection; N.I., not identified; $\Sigma \mathrm{Ni}$, number of panelists.

FIGURE 2 Aromagram of BG2 odor-active compounds obtained by the frequency detection method. [Colour figure can be viewed at wileyonlinelibrary. com]

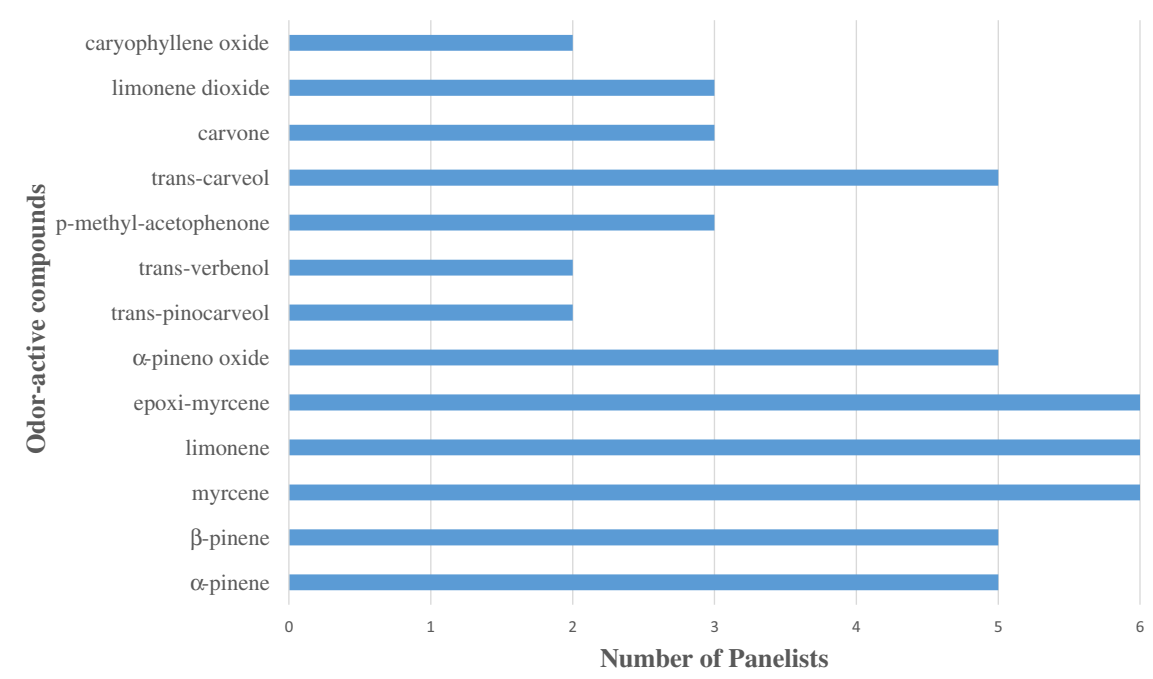

$\alpha$-Pinene, $\beta$-pinene, $\alpha$-pinene oxide, and carvone were identified by five panelists, at $83.3 \%$ of frequency detection. It is noteworthy that most compounds rated the highest intensity score were oxygenated monoterpenes, considered to be the most expressive terpene class used in perfumery. ${ }^{20}$ Furthermore, other compounds identified by the panelists, such as trans-pinocarveol, trans-limonene oxide, trans-verbenol, and trans-carveol, perceived by at least two panelists, also belong to this class, corroborating their importance. It is interesting to note that these oxygenated monoterpenes, important EO odor compounds, have not been described previously for this genus. ${ }^{4,5,25}$ These compounds were associated with the green, herb,

All panelists pointed to an unidentified substance with an IRL of 1115 , suggesting an oxygenated monoterpene. 
spicy, fresh, and camphoraceus olfactory descriptors in B graveolens EOs.

\section{CONCLUSIONS}

Volatile B graveolens essential oil constituents were identified and quantified, and monoterpene hydrocarbons were identified as the major compounds, in contrast to EOs from other species belonging to the same genus, in which sesquiterpene hydrocarbons are described as the main class. The differences in sesquiterpene composition between both EOs demonstrate the difficulty in obtaining standardized raw materials. Sensory analyses and CG-O determinations by the frequency detection method corroborate the main $B$ graveolens EO odor aspects. Finally, this study has presented the first chemical and olfactory characterization results for $B$ graveolens EO, which are promising and may promote the use of this EO.

\section{ACKNOWLEDGEMENTS}

The authors would like to thank Conselho Nacional de Desenvolvimento Científico e Tecnológico (CNPq), Coordenação de Aperfeiçoamento de Nível Superior - Brasil (CAPES) Finance code 001, Fundação de Amparo a Pesquisa do Estado do Rio de Janeiro (FAPERJ) and EMBRAPA for financial support.

\section{CONFLICT OF INTEREST}

The authors declare that they have no conflict of interest.

\section{ORCID}

Ana C. R. Silva (iD https://orcid.org/0000-0001-9456-7056

\section{REFERENCES}

1. Myers N, Mittermeier RA, Mittermeier CG, da Fonseca GAB, Kent J. Biodiversity hotspots for conservation priorities. Nature 2000;403:853-858.

2. Vieira RF, Bizzo HR, Deschamps C. Genetic resources of aromatic plants from Brazil. Isr J Plant Sci. 2010;58(3):263-271.

3. Silva RF, Rezende CM, Santana HCD, Vieira RF, Bizzo HR. Scents from Brazilian Cerrado: chemical composition of the essential oil from the leaves of Hyptis villosa Pohl ex Benth (Lamiaceae). J Essent Oil Res. 2013;25(5):415-418.

4. Goudoum A, Abdou AB, Ngamo LST, Ngassoum MB, Mbofung CMF. Antioxidant activities of essential oil of Bidens pilosa (Linn. Var. Radita) used for the preservation of food qualities in North Cameroon. Food Sci Nutr. 2016;4(5):671-678.

5. Deba F, Xuan TD, Yasuda M, Tawata S. Chemical composition and antioxidant, antibacterial and antifungal activities of the essential oils from Bidens pilosa Linn. var. Radiata. Food Control. 2008;19(4):346-352.

6. Flora do Brasil 2020 em construção. Bidens. Jardim Botânico do Rio de Janeiro. Available in: http://www.floradobrasil.jbrj.gov.br/ reflora/floradobrasil/FB16007. Acessed in Jun 2019.
7. Bringel J, Pastore JFB, Cavalcanti TB. An unusual new species of Bidens (Asteraceae, Coreopsideae) with Its phylogenetic position and taxonomic notes. Syst Bot. 2017;42:301-312.

8. Rahman A, Bajpai VK, Dung NT, Kang SC. Antibacterial and antioxidant activities of the essential oil and methanol extracts of Bidens frondosa Linn. Int J Food Sci Technol. 2011;46:1238-1244.

9. de Oliveira PF, Alves JM, Damasceno JL, et al. Cytotoxicity screening of essential oils in cancer cell lines. Brazilian J Pharmacogn. 2015;25:183-188.

10. Yang J, Sun S, Jiang J, et al. Chemical composition and aromatic profiles of essential oil from Rosa laevigata by GC-MS/GC-O analysis. Adv J Food Sci Technol. 2016;11:147-152.

11. Ocheng F, Bwanga F, Joloba M, et al. Essential oils from Ugandan aromatic medicinal plants: chemical composition and growth inhibitory effects on oral pathogens. Evidence-based Complement Altern Med. 2015; 2015:1-10.

12. Tomczykowa M, Leszczynska K, Tomczyk M, Tryniszewska E, Kalemba D. Composition of the essential oil of Bidens tripartita L. roots and its antibacterial and antifungal activities. J Med Fodd. 2011;14:428-433.

13. Tomczykowa M, Tomczyk M, Jakoniuk P, Tryniszewska E. Antimicrobial and antifungal activities of the extracts and essential oils of Bidens tripartita. Folia Histochem Cytobiol. 2008;46:389-393.

14. Medeiros FCM, Del MC, Vieira RF, et al. Scents from Brazilian Cerrado: chemical composition of the essential oil from Psidium laruotteanum Cambess (Myrtaceae). J Essent Oil Res. 2018;30:253-257.

15. Fontes Vieira R, Bizzo H, Marengo A, Bicchi C, Sgorbini B, Rubiolo P. Volatile profiling of arnicão (Lychnophora salicifolia mart.), a wild medicinal species from Brazilian Cerrado volatile profiling of arnic ao (Lychnophora salicifolia mart.), a wild medicinal species from Brazilian Cerrado. Plant Biosyst. 2019;153:1-8.

16. Edle CWI, Robinson H, Bohlmann F, Ahmed M, King RM, Germany W. Compounds From Bidens graveolens. New York. 1982: 0-2.

17. Silva R, Rezende C, Bizzo H, Santana H, Vieira R, Alves R. Composição do óleo essencial das folhas de Bidens graveolens Mart. (Asteraceae). In: Congresso Latino Americano de Cromatografiaa e Técnicas Relacionadas -COLACRO XIV; 2012:524.

18. Xiao Z, Ma S, Niu Y, Chen F, Yu D. Characterization of odour-active compounds of sweet orange essential oils of different regions by gas chromatography-mass spectrometry, gas chromatography-olfactometry and their correlation with sensory attributes. Flavour Fragr J. 2016;31:41-50.

19. Cicchetti E, Duroure L, Perez M, Sizaire L, Vasseur C. Characterization of odour-active compounds in Timur (Zanthoxylum armatum DC.) fruits from Nepal. Flavour Fragr J. 2017;32:317-329.

20. Costa R, d'Acampora Zellner B, Crupi ML et al. GC-MS, GC-O and enantio-GC investigation of the essential oil of Tarchonanthus camphoratus L. Flavour Fragr J. 2008;23:40-48.

21. Brevard H, Cantergiani E, Cachet T, et al. Guidelines for the quantitative gas chromatography of volatile flavouring substances, from the Working Group on Methods of Analysis of the International Organization of the Flavor Industry (IOFI). Flavour Fragr J. 2011;26:297-299.

22. Cecchini C, Coman MM, Cresci A, et al. Essential oil from fruits and roots of Ferulago campestris (Besser) Grecescu (Apiaceae): composition and antioxidant and anti-Candida activity. Flavour Fragr $\mathrm{J}$. 2010;25:493-502.

23. Adams RP. Identification of Essential Oil Components by Gas Chromatography, 4th edn. Carol Stream, IL: Allured Publishing Corp; 2007.

24. Li HY, Chen XB, Liu QZ, Liu ZL. Chemical composition and insecticidal properties of the essential oil of Bidens frondosa $L$ (Asteraceae) against booklice (Liposcelis bostrychophila). Trop J Pharm Res. 2017;16:171-177. 
25. Nascimento AL, Raggi L, Young MCM, Moreno PRH. Chemical characterization of the volatile compounds of the flowers of Bidens segetum Martius ex Colla (Asteraceae). J Essent Oil Res. 2015;27:70-75.

26. Baser HC, Buchbauer G. Handbook of Essential Oils: Science, Technology and Applications. Boca Raton: CRC Press; 2010:975.

27. Aguiar GP, Carvalho CE, Dias HJ, et al. Antimicrobial activity of selected essential oils against cariogenic bacteria. Nat Prod Res. 2013;27:1668-1672.

28. Figueiredo C, Barroso J, Pedro L, Scheefeer J. Factors affecting secondary metabolite production in plants: volatile components and essential oils. Flavour Fragr J. 2007;22:206-213.
29. Yu HZ, Chen SS. Identification of characteristic aroma-active compounds in steamed mangrove crab (Scylla serrata). Food Res Int. 2010;43:2081-2086.

How to cite this article: Silva ACR, Bizzo HR, Vieira RF, et al. Characterization of volatile and odor-active compounds of the essential oil from Bidens graveolens Mart. (Asteraceae). Flavour Fragr J. 2020;35:79-87. https://doi.org/10.1002/ffj.3538 